\title{
Influence of advanced recipient and donor age on the outcome of corneal transplantation
}

Keryn A Williams, Sylvia M Muehlberg, Rowena F Lewis, Douglas J Coster on behalf of all contributors to the Australian Corneal Graft Registry

\begin{abstract}
Aims-The aims of this study were to examine the influence of advanced recipient and donor age on the long term outcome of corneal transplantation. Methods-Records of 1036 penetrating corneal grafts in recipients aged $\geqslant 80$ years at surgery (defined as the elderly subset) and 8092 donor corneas used for transplantation were obtained from the Australian Corneal Graft Register database. Kaplan-Meier graft survival plots were compared using log rank statistics.

Results-Elderly recipients constituted $15 \%$ of the recipient pool. The major indication for corneal transplantation in the elderly was bullous keratopathy. Graft survival fell with increasing recipient age $(p<0.00001)$; the major cause of graft failure was rejection (33\%). The desired outcome in $51 \%$ of cases was to improve vision and in $42 \%$ of cases to relieve pain; $23 \%$ of elderly recipients achieved a Snellen acuity of $6 / 18$ or better in the grafted eye and $66 \%$ recorded improved acuity after transplantation. Elderly recipients suffered more complications and comorbidities in the grafted eye than did younger recipients. Donor age (stratified in 10 year intervals) did not influence corneal graft survival significantly $(p=0.10)$. Conclusions-Elderly graft recipients fared less well after corneal transplantation than did younger recipients, but outcomes in terms of long term graft survival and visual rehabilitation were still good. Donor age did not affect graft survival. (Br f Ophthalmol 1997;81:835-839)
\end{abstract}

In recent years, developments in anaesthesia and microsurgery have reduced the physiological stress and increased the predictability of corneal transplantation to a point where it can be offered to virtually everyone who might benefit. It is widely accepted that few geographic regions of the world have an excess of human corneas for transplantation, ${ }^{1}$ although concrete information on waiting lists for corneal transplantation is seldom published. Wherever patients are on waiting lists for surgery, the dual issues of fair allocation of donor corneas and of ethical methods of improving the number of donor corneas available for transplantation need to be addressed. ${ }^{2}{ }^{3}$ Restriction of corneal transplantation to younger patients (who are possibly more likely to benefit from the procedure) and relaxation of age based criteria for donor selection may, in theory, alleviate some of the problems associated with insufficient donor supply.

Recipient age is seldom a barrier to corneal transplantation but the impact of age on outcome measures is undetermined. Age may potentially influence wound healing ${ }^{4}$ (although arguments have been mounted to the contrary ${ }^{5}$ ), immunological responsiveness, ${ }^{67}$ and the incidence of postoperative complications. Furthermore, successful corneal transplantation depends on patient cooperation and compliance with medication. The level of cooperation required may be difficult for older patients to achieve and this may be reflected in reduced graft survival. Finally, comorbidities may increase with increasing age, reducing the benefit that might otherwise be achieved though corneal transplantation.

Identification of an upper age limit for corneal donors is an important decision to be made in most eye banks. On the one hand, corneal endothelial cell loss is well known to occur with increasing age ${ }^{8}$ and some endothelial cell loss attendant upon corneal surgery is virtually inevitable. ${ }^{910}$ On the other hand, the substantial redundancy in endothelial cell number when compared with the number required to maintain stromal deturgescence means that many elderly corneas may function perfectly well. ${ }^{11}$

Using information collected prospectively into a large database of corneal grafts with follow up periods extending to 10 years, we sought to examine the long term results of corneal transplantation in elderly recipients. We investigated both Kaplan-Meier graft survival and visual outcome. Further, we examined the influence of increased donor age on long term graft outcome.

\section{Methods}

Grafts entered into the Australian Corneal Graft Registry are followed systematically and prospectively until the graft fails or the recipient dies or is lost to follow up. Graft survival, visual outcome, complications, and comorbidities are all recorded. Detailed descriptions of the operation of the registry have been published elsewhere. ${ }^{12}{ }^{13}$

\section{PATIENT RECORDS}

Information was available on a cohort of 7741 patients who had undergone penetrating corneal transplantation. The study period was 5 May 1985 to 14 May 1996 (11 years). In 1036
Accepted for publication 28 July 1997 


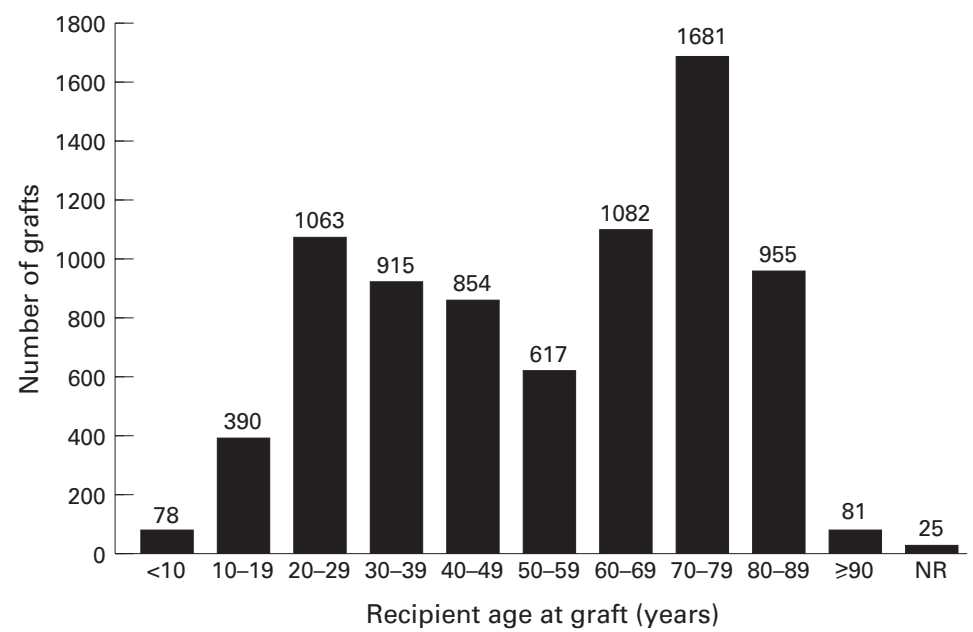

Figure 1 Distribution of recipient ages at graft in a cohort of 7741 patients undergoing penetrating corneal transplantation. $N R=$ not recorded .

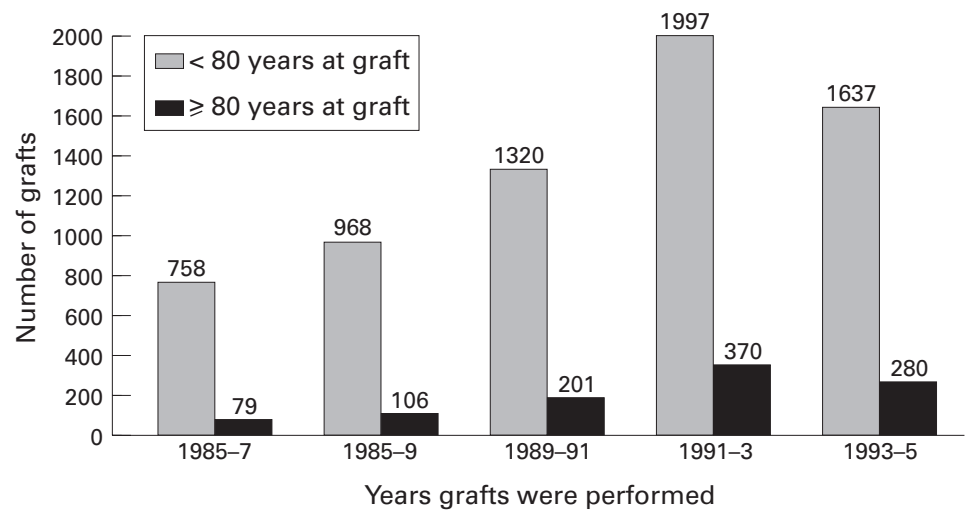

Figure 2 Number of corneal grafts in elderly recipients aged $\geqslant 80$ years at the time of graft compared with those age $<80$ years, showing the influence of calendar years in which the grafts were performed.

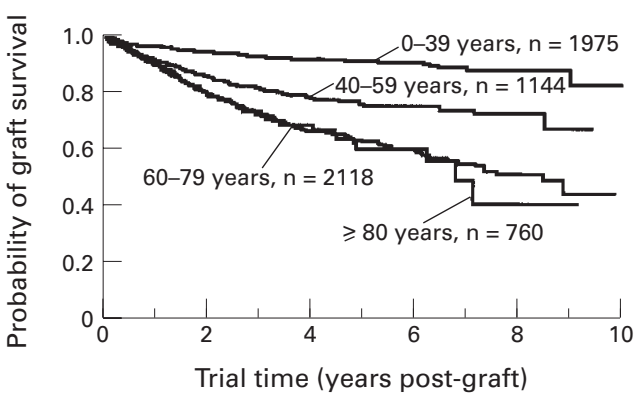

Figure 3 Kaplan-Meier corneal graft survival plots stratified according to recipient age at graft. For each curve, $n=$ number initially at risk.

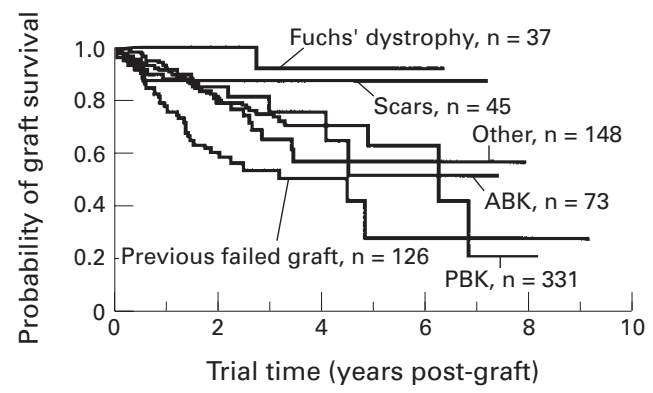

Figure 4 Kaplan-Meier graft survival plots in recipients aged $\geqslant 80$ years at graft, stratified according to the most common indications for transplantation in this subset. For each curve, $n=$ number initially at risk. Scars = corneal scars and opacities; $A B K=$ aphakic bullous keratopathy; $P B K=$ pseudophakic bullous keratopathy.

reaction with corneal infiltrates and spreading corneal oedema in a previously thin, clear graft.

INDICATIONS, COMPLICATIONS, AND COMORBIDITIES

Presenting diseases, indications for graft, postoperative complications, and reasons for graft failure were coded using the ICD.9.CM system (US Department of Health and Human Services). Any development with the potential to compromise graft outcome was considered to be a complication. Postoperative complications were collected in two ways. Firstly, a number of specified complications (for example, rise in intraocular pressure, fixed, dilated pupil, cataract, rejection episode, herpetic recurrence, early changes of bullous keratopathy), refractive and related errors (anisometropia, $\geqslant 5$ dioptres of astigmatism) and factors potentially affecting visual outcome but unrelated to the graft (cataract, aphakia, amblyopia, retinal detachment, cystoid macular oedema, or senile macular degeneration) were listed, requiring a yes/no answer. Secondly, contributors were asked to specify any other relevant complications, information, or departures from their preferred treatment.

\section{STATISTICAL ANALYSIS}

Kaplan-Meier survival plots ${ }^{14}$ were constructed using SPIDA version 6.05 (Macquarie University, Armadale, NSW, Australia). For surviving grafts, trial time was calculated as the number of days between the date of graft and the date on which the patient was last seen. For failed grafts, trial time was calculated as the development of a rejection line (epithelial or endothelial) or a unilateral anterior chamber 
Table 1 Indications for penetrating keratoplasty in recipients aged $\geqslant 80$ years compared with those aged $<80$ years at the time of graft

\begin{tabular}{lcc}
\hline Indication & $\begin{array}{l}\text { No (\%) of recipients aged } \\
\geqslant 80 \text { years }\end{array}$ & $\begin{array}{l}\text { No (\%) of recipients } \\
\text { aged }<80 \text { years }\end{array}$ \\
\hline Keratoconus & $9(>1 \%)$ & $2309(34 \%)$ \\
Bullous keratopathy & $556(54 \%)$ & $1404(21 \%)$ \\
Failed previous graft & $179(17 \%)$ & $1269(19 \%)$ \\
Corneal dystrophy & $90(9 \%)$ & $455(7 \%)$ \\
Corneal scar/opacity & $61(6 \%)$ & $409(6 \%)$ \\
Other & $141(14 \%)$ & $859(13 \%)$ \\
Total & $1036(100 \%)$ & $6705(100 \%)$ \\
\hline
\end{tabular}

Table 2 Desired outcome after corneal transplantation in recipients aged $\geqslant 80$ years compared with those aged $<80$ years at the time of graft

\begin{tabular}{lcl}
\hline Desired outcome & $\begin{array}{l}\text { No (\%) of recipients } \\
\text { aged } \geqslant 80 \text { years }\end{array}$ & $\begin{array}{l}\text { No (\%) of recipients } \\
\text { aged }<80 \text { years }\end{array}$ \\
\hline Improved vision only & $313(51 \%)$ & $3575(77 \%)$ \\
Relief of pain & $263(42 \%)$ & $799(17 \%)$ \\
Structural repair & $39(6 \%)$ & $135(3 \%)$ \\
Multiple reasons & $4(<1 \%)$ & $153(3 \%)$ \\
Total & $619(100 \%)$ & $4043(100 \%)$ \\
\hline
\end{tabular}

${ }^{\star}$ Includes cases where the desired outcome was relief of pain and improvement in vision.

Table 3 Complications and comorbidities affecting the visual potential of the grafted eye in recipients aged $\geqslant 80$ years compared with those aged $<80$ years at the time of graft

\begin{tabular}{lcc}
\hline Complication or comorbidity & $\begin{array}{c}\text { No (\%) aged } \\
\geqslant 80 \text { years affected }\end{array}$ & $\begin{array}{l}\text { No (\%) aged } \\
<80 \text { years affected }\end{array}$ \\
\hline Maculopathy & $203(27 \%)^{\star}$ & $390(7 \%)$ \\
Cystoid macular oedema & $173(23 \%)$ & $430(8 \%)$ \\
Graft failure & $144(19 \%)$ & $841(16 \%)$ \\
Astigmatism >5 D & $123(16 \%)$ & $1103(21 \%)$ \\
Aphakia & $46(6 \%)$ & $163(3 \%)$ \\
Glaucoma & $33(4 \%)$ & $102(2 \%)$ \\
Retinal detachment & $14(2 \%)$ & $83(2 \%)$ \\
Cataract & $11(1 \%)$ & $143(3 \%)$ \\
Anisometropia & $3(<1 \%)$ & $61(1 \%)$ \\
Amblyopia & $3(<1 \%)$ & $182(3 \%)$ \\
Other & $76(10 \%)$ & $543(10 \%)$
\end{tabular}

${ }^{\star}$ Expressed as percentage of cohort with follow up under consideration; any recipient may have more than one complication or comorbidity.

number of days between the date of graft and the date of failure. Kaplan-Meier plots were compared using log rank analysis. ${ }^{15} 16$

\section{Results}

RECIPIENT AGE AT GRAFT

Recipient age at graft in the total cohort of 7741 patients undergoing penetrating corneal transplantation ranged from 27 days to 97 years (Fig 1). The proportion of elderly corneal graft recipients (defined as those $\geqslant 80$ years at

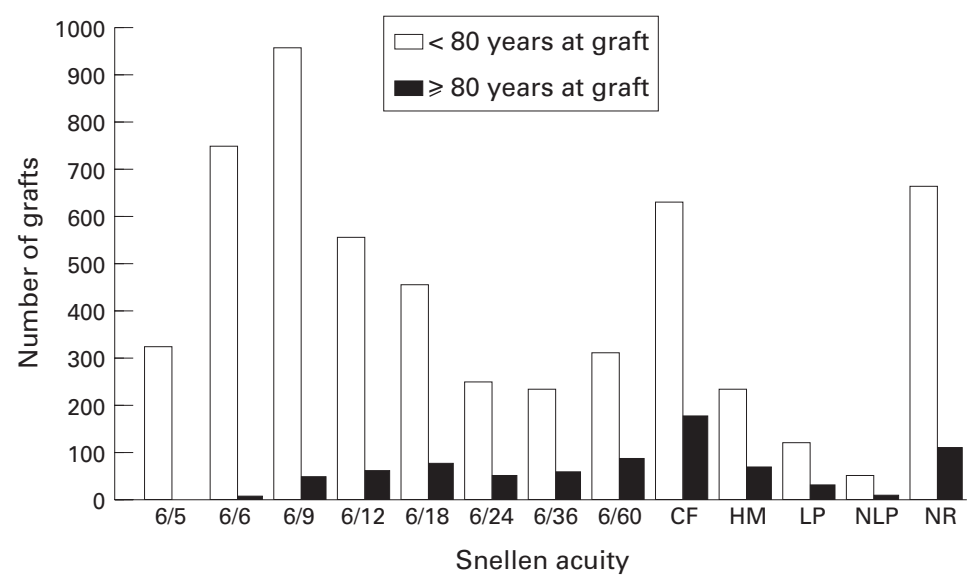

Figure 5 Snellen acuity at the time of most recent follow up for elderly corneal graft recipients ( $\geqslant 80$ years) and for younger recipients ( $<80$ years). $C F=$ counting fingers at 1 metre; HM = hand movements; LP = light perception; NLP = no light perception; NR= not recorded. graft) within the total cohort rose slightly from $9-10 \%$ in $1985-9$ to $15-16 \%$ in $1991-5$ (Fig 2).

INDICATIONS FOR PENETRATING

TRANSPLANTATION IN THE ELDERLY

The indications for penetrating keratoplasty in the subset of elderly recipients are shown in Table 1; indications for graft in the entire recipient cohort are provided for comparison. Bullous keratopathy (83\% pseudophakic and $17 \%$ aphakic) was relatively more important and keratoconus less important as an indication for graft in elderly recipients than for the cohort as a whole.

EFFECT OF RECIPIENT AGE ON CORNEAL GRAFT SURVIVAL

The influence of recipient age on penetrating corneal graft survival in the whole cohort is shown in Figure 3: graft survival fell with increasing recipient age $(\mathrm{p}<0.00001)$. There were too few patients in the subset of recipients aged 80 years or more with keratoconus (Table 1) for a survival plot to be generated specifically for this group. However, when grafts performed for keratoconus were examined in the whole cohort, Kaplan-Meier graft survival for the various age groups (including a group of those aged over 60 years) ranged from 94-98\%, values which did not differ significantly from each other $(\mathrm{p}=0.51)$, data not shown. Kaplan-Meier graft survival plots stratified according to the most common indications for penetrating keratoplasty in elderly recipients are shown in Figure 4: 5 year graft survival was $63 \%$ for recipients grafted for pseudophakic bullous keratopathy, $52 \%$ for aphakic bullous keratopathy, $28 \%$ for previous failed graft, $87 \%$ for corneal scars and opacities, and $57 \%$ for all other indications for graft combined.

The main reasons for corneal graft failure in the elderly subset were irreversible rejection (33\%), endothelial cell failure (24\%), infection $(14 \%)$, or glaucoma $(6 \%)$. In recipients younger than 80 years, the most important reasons were rejection (32\%), endothelial cell failure $(20 \%)$, infection $(14 \%)$, and glaucoma $(8 \%)$.

\section{VISUAL OUTCOME AFTER CORNEAL}

TRANSPLANTATION

The desired outcome of transplantation for the subset of elderly recipients and for the cohort of all recipients is shown in Table 2. Relief of pain (with or without improvement in vision) was a relatively more important outcome than improvement in vision alone in elderly recipients, when compared with desired outcome in younger recipients.

Visual outcome at the time of last follow up for all recipients aged $\geqslant 80$ years at graft compared with data for the entire cohort is shown in Figure 5. Data were unavailable for $11 \%$ of elderly recipients and for $11 \%$ of younger recipients. In the subset of elderly recipients, $14 \%$ achieved a best corrected Snellen acuity of $6 / 12$ or better, $23 \%$ achieved $6 / 18$ or better and $24 \%$ achieved less than 6/60, compared 


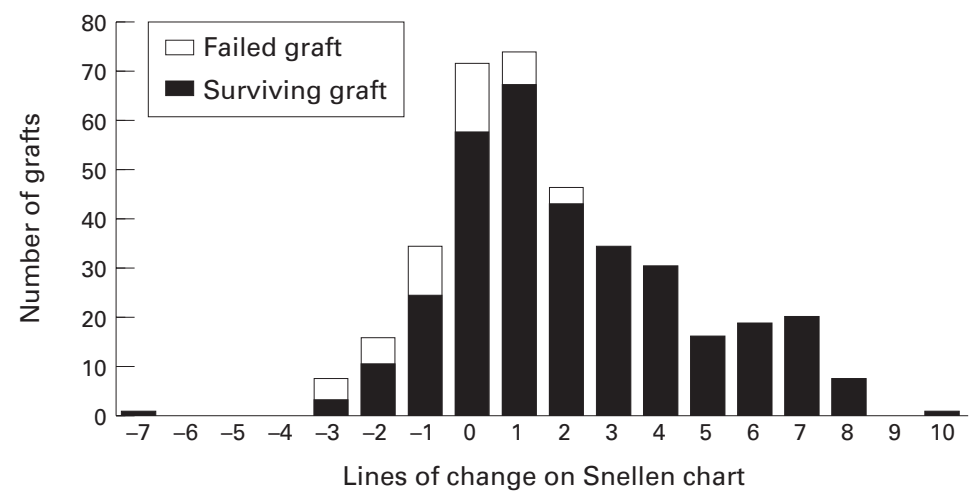

Figure 6 Number of lines of change on the Snellen chart at the time of most recent follow up, compared with Snellen acuity immediately before corneal transplantation, for elderly corneal graft recipients ( $\geqslant 80$ years).

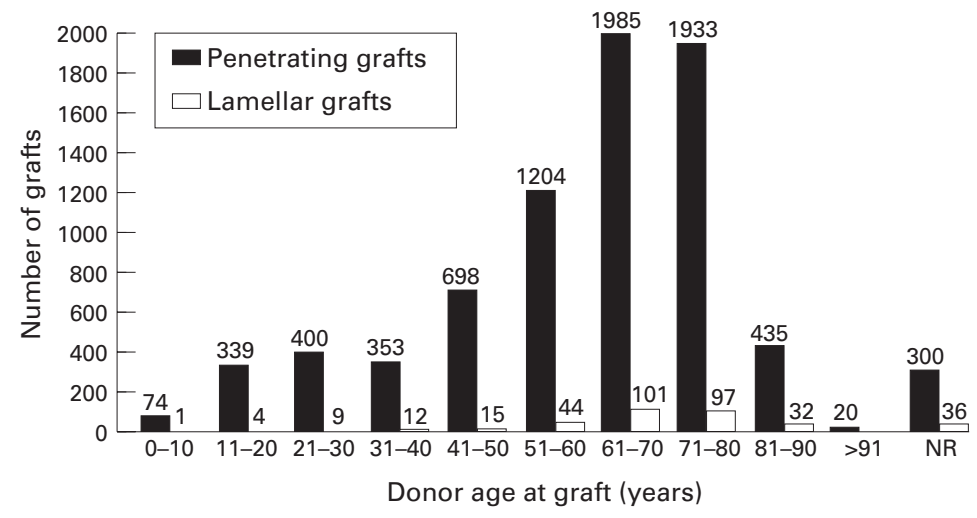

Figure 7 Number of penetrating and lamellar corneal grafts performed using tissue from corneal donors of different ages, stratified in 10 year intervals. $N R=$ not recorded .

with $46 \%, 54 \%$, and $19 \%$ respectively for recipients aged less than 80 years at graft.

To determine whether any improvement in visual acuity had resulted from the transplant procedure, a comparison was made of preoperative Snellen acuity and the postoperative acuity at the time of most recent follow up. The number of lines of change in Snellen acuity after transplantation is shown in Figure 6; failed grafts in which acuity could not be expected to have improved are shown separately from surviving grafts. Overall, 34\% of elderly recipients recorded no change in Snellen acuity or saw worse after graft, while $66 \%$ recorded one or more lines of improvement on the Snellen chart. These data compare with $19 \%$ and $81 \%$ respectively, in the cohort of patients aged less than 80 years.
COMPLICATIONS AND COMORBIDITIES AFFECTING VISUAL OUTCOME

Complications and comorbidities in the grafted eye assessed as having a negative influence on the visual potential of the grafted eye are shown in Table 3. Elderly patients suffered from more comorbidities than did younger recipients, with vision in one in four grafted eyes in the elderly subset being compromised by a retinal disorder.

INFLUENCE OF DONOR AGE ON CORNEAL GRAFT SURVIVAL

A histogram of age at the time of death for donors of corneas used for both penetrating and lamellar corneal grafts is shown in Figure 7. In $4 \%$ of cases, donor age was not reported. Donor age ranged from less than 1 year to over 90 years (median 64 years), with $66 \%$ of donors being in their sixth, seventh, or eighth decade and $6 \%$ being aged over 80 years at death. Only $2.5 \%$ of corneas were collected from multiorgan, brain dead donors but the median age for these donors was 39 years. Kaplan-Meier survival of penetrating corneal grafts stratified according to donor age (in 10 year intervals) is shown in Table 4: donor age exerted no significant effect on graft survival $(p$ $=0.10)$.

\section{Discussion}

Recipients aged 80 years or more constitute an important subset of patients referred for corneal transplantation. Within our database, the proportion of elderly recipients undergoing surgery has increased over a 10 year period and now appears stable at $15-16 \%$. The relative proportions of most indications for corneal transplantation are similar in older and younger recipients, except that bullous keratopathy becomes relatively more important, and keratoconus much less important, in elderly recipients.

Corneal graft survival falls significantly in recipients aged 60 or more years when compared with outcome in younger patients. However, there is no particular difference in survival between those aged 60-79 and those aged 80 years or more. Plainly, the indications for surgery are different in young and older graft recipients and this difference appears to account for most if not all of the difference in graft survival. Older patients tend to suffer from pseudophakic or aphakic bullous keratopathy, or a failed previous graft, indications

Table 4 Graft survival stratified according to donor age in 10 year intervals

\begin{tabular}{|c|c|c|c|c|c|c|c|c|c|}
\hline \multirow{2}{*}{$\begin{array}{l}\text { Donor age } \\
\text { (years) }\end{array}$} & \multicolumn{9}{|c|}{ Probability of graft survival (number at risk) at trial times of: } \\
\hline & 0 years & 1 year & 2 years & 3 years & 4 years & 5 years & 6 years & 7 years & 8 years \\
\hline$<10$ & $100(59)$ & $90(42)$ & $90(27)$ & $90(21)$ & $90(15)$ & $81(9)$ & $81(3)$ & $81(2)$ & $81(1)$ \\
\hline $11-20$ & $100(275)$ & $92(209)$ & 87 (139) & $82(89)$ & $78(68)$ & $78(43)$ & $74(23)$ & $74(12)$ & $74(6)$ \\
\hline $21-30$ & $100(314)$ & $93(225)$ & $87(131)$ & $84(84)$ & $82(59)$ & $80(37)$ & $80(26)$ & $76(14)$ & $67(5)$ \\
\hline $31-40$ & $100(287)$ & $93(203)$ & $88(133)$ & $85(85)$ & $85(50)$ & $85(33)$ & $82(27)$ & $82(20)$ & $82(10)$ \\
\hline $41-50$ & $100(537)$ & $91(375)$ & $86(226)$ & 81 (139) & 79 (97) & $78(62)$ & $78(38)$ & $72(25)$ & $72(16)$ \\
\hline $51-60$ & $100(930)$ & $92(685)$ & $86(436)$ & 81 (287) & 78 (187) & $76(123)$ & $73(77)$ & $71(49)$ & $66(20)$ \\
\hline $61-70$ & $100(1567)$ & $90(1108)$ & $83(688)$ & 79 (437) & $75(272)$ & $72(175)$ & $71(123)$ & $69(72)$ & $68(36)$ \\
\hline $71-80$ & $100(1476)$ & $92(1060)$ & $85(642)$ & $81(403)$ & $74(231)$ & $70(13)$ & $68(82)$ & $65(52)$ & $61(18)$ \\
\hline $81-90$ & $100(318)$ & $91(231)$ & $83(146)$ & $77(79)$ & $75(47)$ & $73(26)$ & $73(12)$ & $64(5)$ & $64(1)$ \\
\hline$>91$ & $100(17)$ & $88(13)$ & $72(8)$ & $72(6)$ & $72(5)$ & $72(5)$ & $72(4)$ & $72(3)$ & $72(2)$ \\
\hline
\end{tabular}


which are acknowledged to compromise outcome at least when compared with keratoconus or the corneal dystrophies. Importantly, we found no significant effect of recipient age when first ipsilateral grafts for keratoconus were considered, and the survival of grafts performed for Fuchs' dystrophy or corneal scarring in the elderly subset was excellent. These findings suggest that advanced recipient age is of itself no particular barrier to corneal graft survival.

The immune system deteriorates with increasing age, ${ }^{6}$ so one might expect irreversible rejection to be less of a problem in elderly recipients than in younger patients. This was not found to be the case and, in fact, the reasons for graft failure in the elderly were very similar to those operating in younger patients.

The desired outcome after corneal transplantation was certainly different for elderly graft recipients when compared with younger recipients. Not surprisingly, given the importance of bullous keratopathy as a major indication for transplantation in the elderly subset, relief of pain was a desired outcome in over $40 \%$ of cases. Improvement in vision was also an important desired outcome in the elderly, and in $66 \%$ of instances where both preoperative and postoperative Snellen acuities were available for comparison, at least some improvement in Snellen acuity was observed after corneal transplantation. However, less than $25 \%$ of elderly recipients achieved a best corrected Snellen acuity of 6/18 after graft, compared with over $50 \%$ in younger recipients. Part of the reason for the generally poorer acuity in older patients may lie with the finding that this subgroup suffers from more retinal comorbidities in the grafted eye than do younger recipients.

Some care is required when translating these findings to the clinical setting. Although graft survival may be decreased in older patients, so too is life expectancy. Further, the level of vision required may in many cases be less than that required by a younger person. Thus, a graft which survives 5 years and allows a reasonable degree of vision to be maintained in the absence of pain may materially help a patient for the remainder of his or her life. Our findings support the use of donor corneas in elderly recipients.

Recent studies have suggested that corneas from quite elderly donors may be acceptable for transplantation provided that corneal endothelial cell density and appearance are normal as judged by specular microscopy. ${ }^{17-19}$ $\mathrm{We}^{1213}$ and others ${ }^{2021}$ have previously shown no significant influence of increasing donor age on graft survival. Our current data are important primarily because we have examined long term graft survival within relatively small age ranges (intervals of a decade) in a large database and still failed to find a significant influence of donor age. That donor age does not influence graft survival at up to 10 years postoperatively encourages a widening of the criteria for donor suitability. Even very elderly donors may provide corneas which function long term without compromise.

This work was supported by: NH \& MRC of Australia, AMHAC, the Ophthalmic Research Institute of Australia. We gratefully acknowledge the voluntary contributions made by 405 ophthalmologists and other professionals to the Australian Corneal Graft Registry.

1 Cavanagh HD. Eye banking 1995: danger and opportunity (editorial). Cornea 1995;14:545-6.

2 Council on Ethical and Judicial Affairs, American Medical Association. Ethical considerations in the allocation of organs and other scarce medical resources among patients. Arch Intern Med 1995;155:29-40.

3 Kliger $\mathrm{CH}$. Use of ethical criteria in medical decision making. Corneal transplantation. Arch Ophthalmol 1995;113: 988-93.

4 Cerimele D, Celleno L, Serri F. Physiological changes in

5 Ashcroft GS, Horan MA, Ferguson MW. The effects of ageing on cutaneous wound healing in mammals. F Anat 1995;

6 Chandra RK. Effect of vitamin and trace-element supplementation on immune responses and infection in elderly mentation on immune responses
subjects. Lancet 1992;340:1124-7.

7 Paganelli R, Quinti I, Fagiolo U, Cossarizza A, Ortolani C, Guerra E, et al. Changes in circulating B cells and mmunoglobulin classes and subclasses in a healthy aged population. Clin Exp Immunol 1992;90:351-4.

8 Murphy C, Alvarado J, Juster R, Maglio M. Prenatal and postnatal cellularity of the human corneal endothelium. A quantitative histologic study. Invest Ophthalmol Vis Sci 1984;25:312-22.

9 Bourne WM, Hodge DO, Nelson LR. Corneal endothelium five years after transplantation. Am f Ophthalmol 1994;118: 185-196.

10 Tuft SJ, Coster DJ. The corneal endothelium. Eye 1990;4:389-424.

11 American Academy of Ophthalmology. Ophthalmic procedures assessment. Corneal endothelial photography. Ophthalmology 1991;98:1464-8.

12 Williams KA, Roder D, Esterman A, Muehlberg SM, Coster DJ. Factors predictive of comeal graft survival: report from the Australian Comeal Graft Registry. Ophthalmology 1992;99:403-14.

13 Williams KA, Muehlberg SM, Wing SJ, Coster DJ. The Australian Corneal Graft Registry, 1990-1992 report. Aust NZ F Ophthalmol 1993;21 (suppl):1-48.

14 Kaplan EL, Meier P. Nonparametric estimation from incomplete observations. F Am Stat Assoc 1958;53:475-81.

5 Peto R, Pike MC, Armitage P, Breslow NE, Cox DR, Howard SV, et al. Design and analysis of randomized clinical trials requiring prolonged observation of each patient. I Introduction and design. Br f Cancer 1976;34:585-612.

16 Peto R, Pike MC, Armitage P, Breslow NE, Cox DR, Howard SV, et al. Design and analysis of randomized clinical trials requiring prolonged observation of each patient. II cal trials requiring prolonged observation of each patie

17 Mattern RM, Heck EL, Cavanagh HD. The impact on tissue utilization of screening donor corneas by specular sue utilization of screening donor corneas by specular
microscopy at the University of Texas Southwestern Medimicroscopy at the University of Texas

18 Chu W, Dahl P, O’Neill MJ. Benefits of specular microscopy in evaluating eye donors aged 66 and older. Cornea 1995;14:568-70.

19 Moyes AL, Holland EJ, Palmon FE, Dvorak JA, Doughman DJ. Tissue utilization at the Minnesota Lions' Eye Bank. Cornea 1995;14:571-77.

20 Maguire MG, Stark WJ, Gottsch JD, Stulting RD, Sugar A, Fink NE, et al. Risk factors for corneal graft failure and rejection in the collaborative corneal transplantation studies. Collaborative Corneal Transplantation Studies Research Group. Ophthalmology 1994;101:1536-47.

21 Vail A, Gore SM, Bradley BA, Easty DL, Rogers CA, Armitage WJ. Influence of donor and histocompatibility factors on corneal graft outcome. Transplantation 1994;58: 1210-6. 